JCC

9,1

\section{Managing team coordination incentives: the effect of payoff differentials}

\author{
Madjid Tavana
}

Business Systems and Analytics Department, La Salle University, Philadelphia, PA, USA and Business Information Systems Department, Faculty of Business Administration and Economics, University of Paderborn, Paderborn, Germany

Debora Di Caprio

Department of Mathematics and Statistics, York University, Toronto, Canada and Polo Tecnologico IISS G. Galilei, Bolzano, Italy, and

Francisco J. Santos-Arteaga

School of Economics and Management, Free University of Bolzano, Bolzano, Italy and Instituto Complutense de Estudios Internacionales, Universidad Complutense de Madrid, Pozuelo, Spain

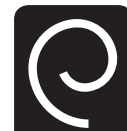

Emerald

Journal of Centrum Cathedra: The Business and Economics Research Journal

Vol. 9 No. 1, 2016

pp. $52-70$

Emerald Group Publishing Limited 1851-6599

DOI 10.1108/JCC-08-2016-0003

\begin{abstract}
Purpose - The current paper aims to present a formal model illustrating how payoff imbalances among the members of a team of decision makers (DMs) who must undertake a project condition the final outcome obtained. This result builds on the fact that payoffs imbalances would lead to different performance levels among the employees and managers who compose a team. The analysis is applied to a strategic environment, where a project requiring coordination among the DMs within the team must be developed.

Design/methodology/approach - The intuition behind the strategic framework on which the results are based is twofold. The authors build on the literature on social comparisons and assume that employees and managers acquire information on the payoffs received by other members of the team while being affected by the resulting comparisons, and they follow the economic literature on firm boundaries determined via incomplete contracts. In this case, employees and managers may underperform if they feel aggrieved by the outcome of the contract giving place to deadweight losses when developing the project.

Findings - The authors illustrate how a team-based performance reward structure may lead to a coordinated equilibrium even when team managers and employees receive different payoffs and exhibit shading incentives based on the payoff differentials between them. The authors will also illustrate how identical shading intensities by both groups of DMs imply that shading by the managers imposes a

(C) Madjid Tavana, Debora Di Caprio and Francisco J. Santos-Arteaga. Published in Journal of Centrum Cathedra: The Business and Economics Research Journal. Published by Emerald Group Publishing Limited. This article is published under the Creative Commons Attribution (CCBY 4.0) licence. Anyone may reproduce, distribute, translate and create derivative works of this article (for both commercial \& non-commercial purposes), subject to full attribution to the original publication and authors. The full terms of this licence may be seen at http://creativecommons.org/ licenses/by/4.0/legalcode
\end{abstract}

JEL classification - D23, L23, D81

The authors wish to express their gratitude to the Editor-in-Chief and the anonymous reviewers for their helpful comments on earlier drafts. 
lower cost on the profit structure of the firm because it leads to a lower decrease in the cooperation incentives of the other members of the team. Finally, the authors show how differences in shading intensity between both types of DMs trigger a strategic defect mechanism within the team that determines the outcome of the project.

Originality/value - The novel environment of team cooperation and defection through shading introduced in this paper is designed to deal with the strategic decisions taken by DMs when undertaking a project within a group. In particular, the intensity of shading applied by the DMs will be endogenously determined by the relative payoffs received, which allows to account for different scenarios, where relative payoff differentials among DMs determine the outcome of the project.

Keywords Strategic performance, Payoff differentials, Shading incentives, Team coordination

Paper type Research paper

\section{Introduction}

The coordination of incentives within a group of heterogeneous decision makers (DMs) constitutes one of the main research topics in agency theory (Jensen and Meckling, 1976; Holmstrom, 1979; Bamberg and Spremann, 1987; Laffont and Martimort, 2001; Gibbons and Roberts, 2013). In particular, the strategic payoffs made to individuals within a research team implies that a minimum capacity is required on the side of the firm to measure the contribution of each one of the team members. That is, absent team production, employees and managers, as well as the firm, should be able to observe and verify each other's relative contributions to the final output (Alchian and Demsetz, 1972). This monitoring capacity allows for specific individualized payoffs being assigned to each worker as a function of their contributions.

On the other hand, it follows from agency theory that firms are more likely to use team-based performance payoffs when coordination across employees constitutes an important part of the production process and the observability of individual effort is limited (Larkin et al., 2012). However, even within a group, payoff differences will arise among its members or DMs, who we will differentiate between managers and employees with the former receiving a higher compensation payoff than the latter. The existence of payoff imbalances will be assumed to cause frictions among the DMs composing a team, though their effect could be mitigated to a certain extent through the involvement of firms in high performance work system practices (Afcha Chavez, 2014). These frictions will lead to the underperformance of those feeling aggrieved by the existing differences in payoffs.

The intuition for this assumption follows from the strategic management literature, which, at the same time, is based on the results obtained by the psychology literature on social comparisons. The literature on social comparison follows from the fact that DMs generally acquire information on other individuals who are similar to them and are affected by the resulting comparisons (Festinger, 1954; Homans, 1961; Suls and Wheeler, 2000; Garcia et al., 2013). These theories assert that people care about inequity and react negatively to outcomes they deem unfair at the organizational level (Pérez-Arechaederra et al., 2014). As a result, individuals will exert efforts to reduce negative feelings proportionate with the inequity they perceive (Adams, 1963).

Economists and management scholars have argued that these comparisons may lead to envy and incentivize sabotage among the workers of a given organization (Nickerson and Zenger, 2008; Bartling and von Siemens, 2010; Pepper et al., 2015). The importance of social comparisons in terms of effort reduction and unethical behavior has been empirically illustrated by Blinder and Choi (1990), Gino and Pierce (2010) and Cohn et al.
Managing team

coordination incentives 
(2012), among others. Moreover, this phenomenon has also been shown to derive in the escalation of executives' wages and those of the employees within a given firm (Faulkender and Yang, 2010).

Additional information in the form of firms' and employees' knowledge about the pay of other employees, together with the resulting incentives add a new source of friction to the traditional approach to agency costs (Kostova et al., 2016). That is, "when deciding how much effort to exude, workers respond not only to their own payoff but also to pay relative to their peers as they socially compare" (Larkin et al., 2012, p. 1200-1201). In this regard, Nickerson and Zenger (2008) describe the existence of managerial diseconomies of scale and scope because of the increment of social comparison and differential compensation costs as firms and the hierarchies within them expand. This is a particularly complex problem given the multiple levels at which projects generally interact within an organization (Foss and Nielsen, 2012; Foss and Weber, 2016). As Nickerson and Zenger (2008, p. 1437) explain:

In a team production setting, individual contributions are of necessity subjectively determined. Consequently, if managers assign pay based on these subjective evaluations, this engenders influence activities because managerial subjectivity can be blamed for differences in pay. Additionally, individuals without access to verifiable information rather easily develop inflated perceptions of their marginal contributions (Meyer, 1975; Zenger, 1994), which may amplify willingness to engage in influence activities. Moreover, team production makes feasible other behavioral strategies like noncooperative behavior and sabotage as well as shirking that are not effective in the absence of team production.

The current paper introduces a novel strategic environment of team cooperation and defection through shading, which is designed to deal with the decisions that are taken by DMs when undertaking a project within a group. In our model, the intensity of the shading applied by the DMs will depend on the relative payoffs received. This endogeneity in the intensity of shading allows the model to account for a variety of scenarios, where the relative payoff differentials among DMs determine the equilibrium and the outcome of the project. Moreover, our model relates directly to the principal-agent literature in economics, dealing with the design of optimal contract mechanisms that guarantee the cooperation between the parties involved throughout the corresponding process.

The rest of the paper proceeds as follows. The next section describes the basic strategic environment considered in the literature, where the intensity of shading is independent of payoff differentials between managers and employees. The third section endogenizes the shading intensity of DMs. The strategic consequences from this modification are intuitively described through the resulting set of games presented in the fourth section. The fifth section adds further intuition by providing some numerical examples, whereas the sixth one defines formally the defect probabilities arising from the mixed strategy equilibria of this set of games. The last section concludes and suggests potential extensions.

\section{Basic ad hoc shading environment}

The literature on strategic management and social comparisons described in the previous section complements the principal-agent approach followed in the economic one. This latter type of models address the corresponding agency problems through the design of contracts that aim at moderating the frictions arising between DMs because of 
conflicting interests and asymmetric information (Hart and Holmstrom, 2010). The intuition behind these models follows from the "contracts as reference points" approach of Hart and Moore (2008). According to this approach, a contract agreed upon by managers and employees under competitive conditions determines their individual senses of entitlement. That is, each group of DMs interprets the contract in a way that is most favorable to its interests. When one of the groups of DMs does not get the most favored outcome from the contract, it will feel aggrieved, and its members will shade by underperforming and sabotaging the potential outcome of the project, creating deadweight losses. In this way, the findings on social comparison obtained by the psychology literature have been incorporated by the economics and management ones to analyze incentive differentials among the DMs and the resulting shading problems.

Clearly, potential shading activities taking place whenever a DM feels aggrieved remain outside the scope of the original contract. Note also that, if firms had the capacity to monitor the contribution of the DMs to the outcome of the project, they could condition their payoffs on the contributions observed. This monitoring capacity on the side of the firms would mitigate the incentives of DMs to shade. In this regard, Hart and Holmstrom (2010) address conflicting interests among the DMs by adopting an organizational form to mitigate the effect of shading. However, the intensity of the shading parameter defining the underperformance of the DMs is assumed exogenous to the payoff differentials arising between them.

Consider a group project that requires the cooperation of at least one of the subsets of DMs' types, either the managers or the employees, to be undertaken and finalized. If both subsets of DMs defect, then the project cannot be undertaken or fails to be correctly developed and both types of DMs face severe consequences (retaliation) from the firm. Thus, the DMs face a coordination game, where the cooperation of at least a subset of them is required to prevent the project from failing. The differences in payoffs among the DMs composing a given team suggest that shading incentives do not necessarily prevent the existence of a cooperative equilibrium, though they may damage the outcome of the project severely. This latter effect is translated into the expected profits of the firm, which may suffer a considerable decrease whenever a group of DMs shades.

The basic decision stages leading to the coordination game played by both types of DMs are summarized in Figure 1 and defined as follows:

- The managers of the team observe the values of the payoff variables $\alpha$ and $\beta$ that will be respectively received by both groups of DMs whenever the project is

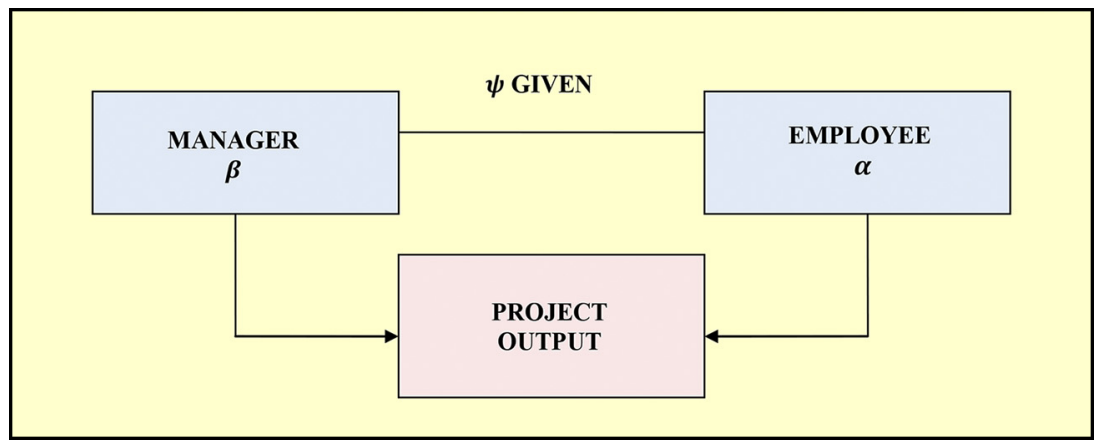

Figure 1. Determination of project output for a given shading intensity 
JCC

9,1

\section{6}

completed. They consider the given value of the shading parameter $\psi$ that will increase their subjective compensation in case they deem the existing payoff differential to be insufficient and decide to underperform by shading.

- The employees follow a similar reasoning after observing the relative values of the payoff variables $\alpha$ and $\beta$. They will also consider the given value of the shading parameter $\psi$ when deciding whether or not to defect on the coordination of the project. In this case, they will defect and underperform by shading if they deem the payoff differential on the side of the managers to be excessive.

- Given the above payoff differences in $\alpha$ and $\beta$, managers and employees decide whether or not to cooperate after accounting for the subjective compensation from underperforming, as well as the resulting shading costs imposed on the firm. The intensity of their shading is exogenously determined and does not depend on the magnitude of the differences between payoffs.

- The shading decision of both DMs has a direct negative effect on the expected output derived from the project and, therefore, the profits attained by the firm.

The model described through this section summarizes the main characteristics of the principal-agent approach followed in the economic literature (Hart and Holmstrom, 2010; Chion and Charles, 2016) and sets the basis for the development of our formal environment, where DMs will be able to choose the intensity of their shading parameters as a function of the payoff differentials received from the completion of the project. Note that a fixed value of the shading parameter imposes $a d$ hoc the equilibrium structure of the coordination strategic environment. It also ignores the main points derived from the literature on social comparison regarding the intensity of shading applied by the DMs. These findings lead to the extension presented in the following section.

\section{Endogenizing the shading intensity}

We illustrated in the introduction how the literature on social comparison allows us to justify at the psychological, managerial and empirical levels the fact that the value of the shading parameter should be endogenously defined based on the payoff differentials arising between the DMs composing a group. Despite the findings reported by the literature on social comparison and the acknowledgement received in the management one, the strategic environment introduced in the economic literature assumes that the resulting cooperation incentives are exogenously determined de facto by nature. That is, the intensity of the shading parameter that determines the equilibrium achieved and the resulting project output does not follow from the interactions taking place among the DMs composing a group but is exogenously given ex ante. This framework was described in Figure 1.

Figure 2 illustrates the process determining the cooperation strategy of both DMs based on the endogenously defined values of the shading parameter $\psi^{M}(\alpha, \beta)$ and $\psi^{e}$ $(\alpha, \beta)$, where the superscripts refer to the managers and the employees, respectively. These shading parameters become a function of the relative payoffs received by each type of DM and their subjective evaluations of this compensational difference (Nickerson and Zenger, 2008). Note that each DM has complete information about the payoff received by the other ones, so both types of DMs know the exact values of $\alpha$ and $\beta$ and are able to calculate the changes in the payoffs derived from either cooperating or shading. 

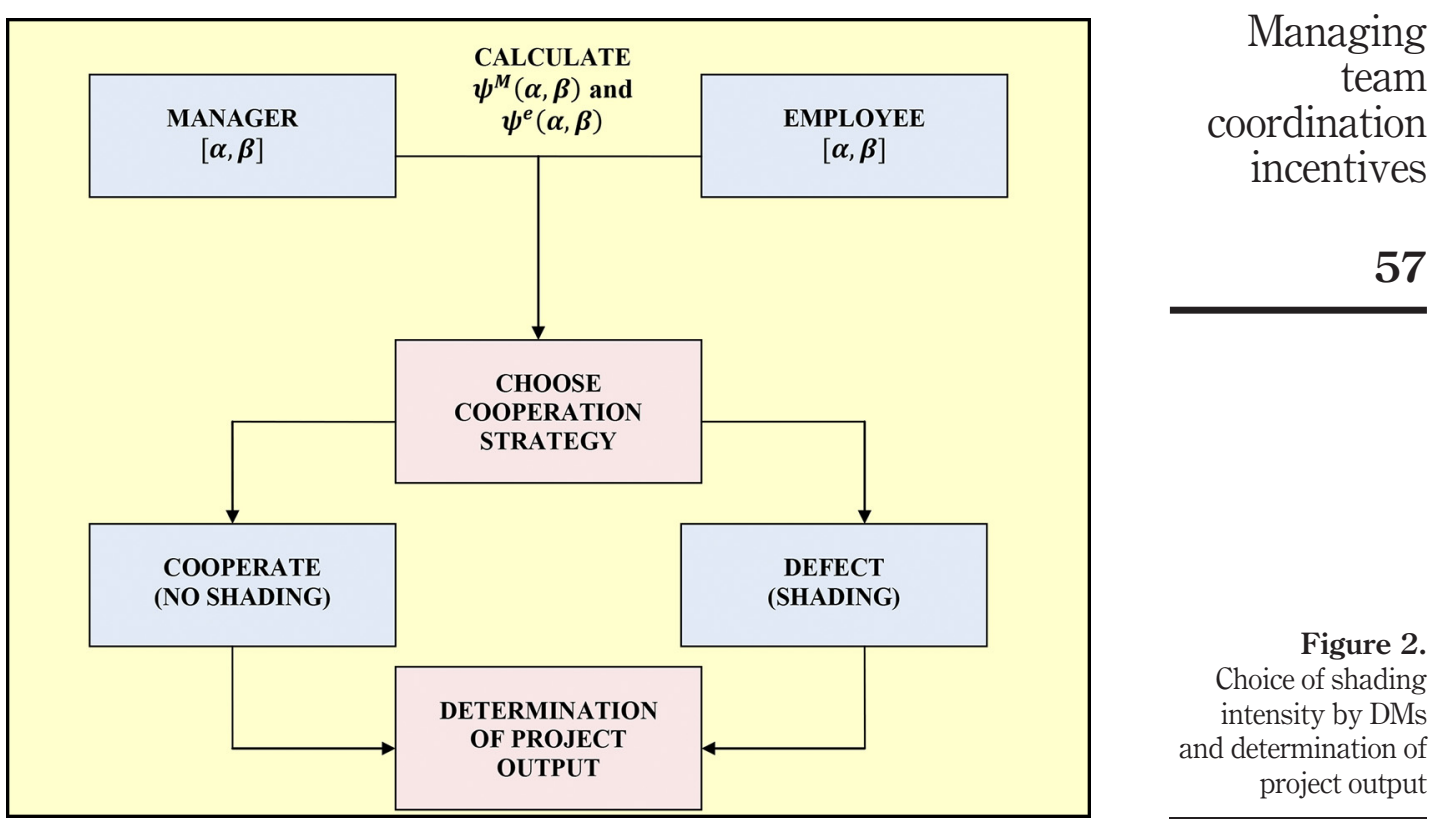

Thus, as Figure 2 shows, given perfect information regarding the payoffs, both types of DMs will calculate their cooperation and shading incentives beforehand and, as a result, choose whether to cooperate or defect when developing the project. If information was not perfect, particularly so when determining the calculation of the shading $\psi$ variables, then subjective expectations must be included to determine the set of potential equilibria of the coordination game. We consider this potential extension in the final sections of the paper.

The decision stages leading to the coordination game played by both DMs can be defined as follows:

- The managers of the team observe the values of the payoff variables $\alpha$ and $\beta$ that will be received whenever the project is completed. They calculate the value of the shading parameter $\psi^{M}(\alpha, \beta)$, whose intensity is based on the differences in payoffs between them and the employees. The value of $\psi^{M}(\alpha, \beta)$ will increase their subjective compensation in case they deem the payoff differential to be insufficient and decide to underperform by shading.

- The employees follow a similar reasoning after observing the relative values of the payoff variables $\alpha$ and $\beta$. They will also calculate and consider the intensity of their shading parameter $\psi^{e}(\alpha, \beta)$ when deciding whether or not to defect on the coordination of the project. In this case, they will defect if they deem the payoff differential between them and the managers to be excessive.

- Given the payoff variables $\alpha$ and $\beta$, managers and employees decide whether or not to cooperate after computing $\psi^{M}(\alpha, \beta)$ and $\psi^{e}(\alpha, \beta)$. The intensity of their shading is directly determined by the magnitude of the differences 
JCC

9,1

58

Figure 3.

Cooperation environment based on shading arising from social comparison

\section{Figure 4.}

Payoff differential limits determining the shading incentives of the managers and the employees between payoffs and the subjective effect that this difference has on each group of DMs.

- The shading decision of both types of DMs has a direct negative effect on the expected output derived from the project and, therefore, on the profits attained by the firm.

- The flowchart presented in Figure 3 describes the incentives of both types of DMs to shade depending on the relative differences in the $\alpha$ and $\beta$ payoffs received.

The cooperation incentives of DMs are based on social comparisons, which determine the intensity of their shading parameters $\psi^{M}(\alpha, \beta)$ and $\psi^{e}(\alpha, \beta)$. The following figure describes the incentives of DMs to underperform through shading as a function of the payoff differentials between both types of DMs.

The strategic structure defined in Figure 4 reads as follows. Employees have an incentive to underperform whenever the difference between their payoff $\alpha$ and that of the manager exceeds $\bar{\alpha}$. Thus, any payoff of $\beta$ to the manager located to the right of the $\bar{\alpha}$ value in Figure 4 will cause the employees to shade. The larger to the right of the $\bar{\alpha}$ value, the higher the intensity of shading applied by the employees.
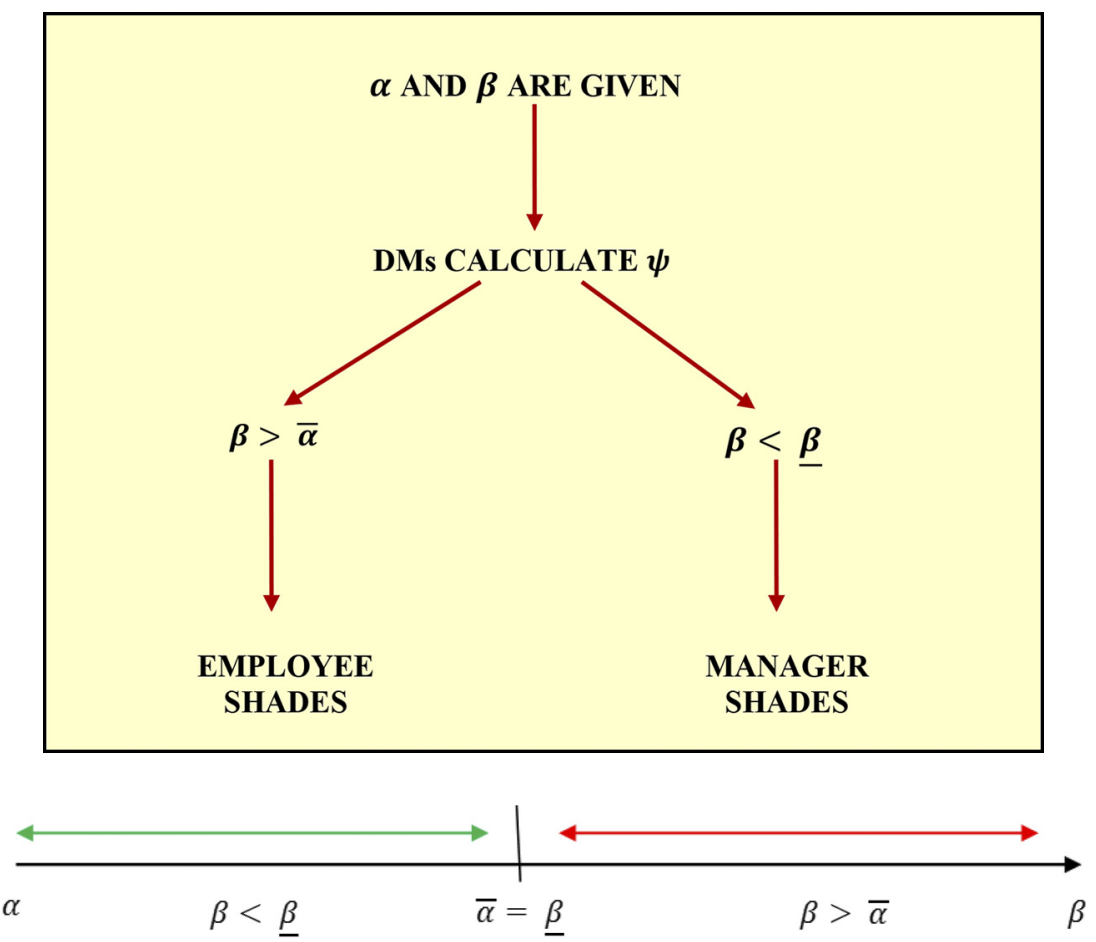

Note: Adjacent shading areas 
The shading incentives of the manager follow a similar intuition. In this case, the managers require a payoff at least as high as $\underline{\beta}$ over the one received by the employees to perform correctly. Any playoff lower than $\underline{\beta}$ would not be considered to be sufficiently high and will lead the managers to underperform by shading. The lower their wage, i.e. the closer to $\alpha$, the higher the intensity of their shading.

For expositional simplicity, we will mainly focus throughout the paper on the $\bar{\alpha}=$ $\beta$ scenario. Note that, in this case, only one type of DM will have an incentive to underperform at a given time, either the employee or the manager. Differences in the shading limits $\bar{\alpha}$ and $\underline{\beta}$ between both types of DMs would allow for scenarios, where either both $(\bar{\alpha}<\beta)$ or none of them $(\bar{\alpha}>\beta)$ have an incentive to shade. These latter scenarios can be easily derived and analyzed as particular extensions of the current one.

For example, Figure 5 illustrates the setting, where both types of DMs have an incentive to shade within the $[\bar{\alpha}, \underline{\beta}]$ subset. As a result, both types of DMs will experience an increase in the defect probability determining their mixed strategy equilibria within the corresponding coordination game. A similar intuition applies to the $[\bar{\alpha}, \underline{\beta}]$ environment presented in Figure 6. In this case, none of the DMs will have an incentive to shade within the resulting $[\beta, \bar{\alpha}]$ subset, eliminating the defect probability (though not the partial defect equilibria) from the mixed strategies of both types of DMs.

It should be noted that we will not differentiate the cumulative effect that employees may have on the output of the project from that of the managers, who account for a lower relative number within the set of DMs. On the other hand, because of their higher position within the hierarchy of the firm, managers may inflict more damage on the output of the project when shading. In the current setting, the intensity of the shading parameter will be used to determine the size of the effect on the final output. Note, however, that both frameworks could be easily analyzed as an extension of the current model.

\section{Game theoretical structure: basic environment}

Independently of the project considered, coordination constitutes an agreement taken among the DMs to develop a given project and implies that different payoffs will be received by the managers and the employees. Defection by one type of DM would

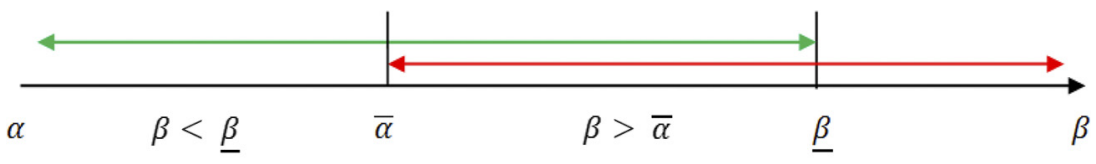

Note: Overlapping shading areas

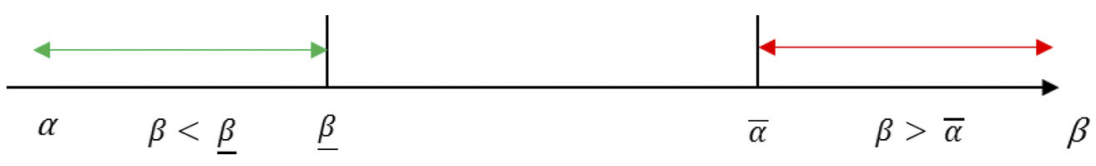

Note: Disjoint shading areas

Figure 5.

Payoff differential limits determining the shading incentives of the managers and the employees

Figure 6. Payoff differential limits determining the shading incentives of the managers and the employees 
JCC

9,1

60

increase their subjectively valued compensation and may or may not reduce the payoff received by the other type. That is, because partial defection will damage the outcome obtained from the project a subsequent decrease in payoffs may be implemented by the firm.

However, the equilibria of the games that we consider in this paper do not depend on this fact, as we will illustrate numerically in the next section. That is, we have concentrated on the defect probabilities that arise from the mixed strategies of either the managers or the employees to contain the shading incentives of the other group of DMs. Given the strategic environment considered, the equilibrium probabilities defining the mixed strategies of the DMs with an incentive to shade are independent from such a modification in the payoffs of the other group of DMs. Finally, we will assume that if both types of DMs defect, then the project cannot be developed, and the firm implements disciplinary measures to both types of DMs.

Table I presents the coordination game that takes place between employees and managers based on the strategic decision process described in the previous paragraph and Figure 2. Accordingly, the entries of Table I define the payoffs received by each type of DM based on the coordination decision taken by the employees and managers within the project.

The payoff entrances composing the matrix have been simplified to provide a more intuitive description without modifying the results obtained. Note that the DMs defecting will receive a compensation payoff determined by the intensity of their respective shading parameters, either $\psi^{M}(\alpha, \beta)$ or $\psi^{e}(\alpha, \beta)$. We will use the variables $\gamma$ and $\Delta$ to define the mixed equilibrium strategies of the employees and the managers, respectively.

It should be highlighted that throughout the rest of the paper, we will explicitly differentiate between the shading incentives of a type of DMs and the resulting defect probabilities that arise from the mixed strategy equilibrium of the other type of DMs. Both of them imply shading by a type of DM, but the latter arise as an equilibrium consequence to mitigate the initial shading incentives displayed by the other type of DMs.

Whenever a partial defection equilibrium is reached, we will assume that the shading parameter provides a positive compensation to the DMs who shade. This assumption leads to an increase in the shading incentives of the DMs when feeling aggrieved. At the same time, as stated at the beginning of this section, those DMs who cooperate when the others defect do not suffer any payoff punishment from the firm. In this regard, it could be assumed that whenever a subset of DMs defect, all the DMs are punished by the firm. If this were the case, our setting would reflect a situation where the subjective compensation from shading outweighs the punishment inflicted by the firm. As will be clear from the analysis, if the firm is able to identify the defectors and reduce their

Table I.

Coordination-based payoffs received by employees and managers

\begin{tabular}{llccc}
\hline & & & Managers & \\
& & $\begin{array}{c}\Delta \\
\text { Defect }\end{array}$ & $\begin{array}{c}(1-\Delta) \\
\text { Cooperate }\end{array}$ \\
\hline Employees & $\gamma$ & Defect & $0 ; 0$ & $\alpha+\psi^{e} ; \beta$ \\
& $(1-\gamma)$ & Cooperate & $\alpha ; \beta+\psi^{M}$ & $\alpha ; \beta$ \\
\hline
\end{tabular}


payoffs accordingly, a cooperative strategy would define the unique dominant Nash equilibrium of the coordination game.

When considering the environment described in Figures 3 and 4, the following payoff matrices arise. Consider first the payoff setting described in Table II. In this case, $\beta>\bar{\alpha}$ and only the employees have an incentive to defect because of the substantial payoff imbalances relative to the rewards obtained by the managers. In this case, $\psi^{e}>0$ and $\psi^{M}=0$.

On the other hand, only the managers have an incentive to defect within the $\beta<\underline{\beta}$ setting described in Table III. In this case, the managers consider the difference in payoffs with respect to the employees insufficient. Thus, $\psi^{e}=0$ and $\psi^{M}>0$.

The Nash equilibria arising from both these settings are easy to identify and given by the (defect, cooperate) and (cooperate, defect) strategy pairs. That is, both games lead to the same set of pure Nash equilibria. However, the mixed strategy equilibria differ between both settings. The main strategic consequences following from these differences are better illustrated numerically.

\section{Numerical equilibrium examples}

The following numerical examples have been introduced to provide an intuitive description of the main results presented in the next section. Consider first the scenario presented in Table IV, which provides a numerical version of the $\beta>\bar{\alpha}$ strategic framework described in Table II.

Note that, in this case, the employees have an incentive to defect but not the managers. The payoff imbalances are sufficiently large for the employees to shade by underperforming. The magnitude of these imbalances defines the intensity of shading

\begin{tabular}{|c|c|c|c|c|}
\hline & & & \multicolumn{2}{|c|}{ Managers } \\
\hline & & & $\begin{array}{c}\Delta \\
\text { Defect }\end{array}$ & $\begin{array}{c}(1-\Delta) \\
\text { Cooperate }\end{array}$ \\
\hline Employees & $\begin{array}{c}\gamma \\
(1-\gamma)\end{array}$ & $\begin{array}{l}\text { Defect } \\
\text { Cooperate }\end{array}$ & $\begin{array}{l}0 ; 0 \\
\alpha ; \beta\end{array}$ & $\begin{array}{c}\alpha+\psi^{e} ; \beta \\
\alpha ; \beta\end{array}$ \\
\hline
\end{tabular}

Table II. Coordination-based payoffs within the $\beta>\bar{\alpha}$ framework: employees defect incentives

\begin{tabular}{|c|c|c|c|c|c|}
\hline & & & \multicolumn{2}{|c|}{ Managers } & \multirow{3}{*}{$\begin{array}{r}\text { Table III. } \\
\text { Coordination-based } \\
\text { payoffs within the } \beta \\
<\underline{\beta} \text { framework: } \\
\text { manager defect } \\
\text { incentives }\end{array}$} \\
\hline & & & $\begin{array}{c}\Delta \\
\text { Defect }\end{array}$ & $\begin{array}{c}(1-\Delta) \\
\text { Cooperate }\end{array}$ & \\
\hline \multirow[t]{3}{*}{ Employees } & $\begin{array}{c}\gamma \\
(1-\gamma)\end{array}$ & $\begin{array}{l}\text { Defect } \\
\text { Cooperate }\end{array}$ & $\begin{array}{c}0 ; 0 \\
\alpha ; \beta+\psi^{M}\end{array}$ & $\begin{array}{l}\alpha ; \beta \\
\alpha ; \beta\end{array}$ & \\
\hline & & & \multicolumn{2}{|c|}{ Managers } & Table IV. \\
\hline & & & $\begin{array}{c}\Delta \\
\text { Defect }\end{array}$ & $\begin{array}{c}(1-\Delta) \\
\text { Cooperate }\end{array}$ & $\begin{array}{l}\text { Coordination-based } \\
\text { payoffs within the }\end{array}$ \\
\hline Employees & $\begin{array}{c}\gamma \\
(1-\gamma)\end{array}$ & Defect & $\begin{array}{l}0 ; 0 \\
2.3\end{array}$ & $3 ; 3$ & employees defect \\
\hline
\end{tabular}


JCC

9,1

62

by the employees. At the same time, this intensity determines the value of the payoff obtained from defecting but does not modify the set of Nash equilibria of the game. As stated in the previous section, the pure Nash equilibria of the game are given by the (defect, cooperate) and (cooperate, defect) strategy pairs. In this case, a mixed strategy Nash equilibrium can also be derived from the following equations:

$$
\begin{aligned}
& 3(1-\gamma)=3 \\
& 3(1-\Delta)=2
\end{aligned}
$$

These equations lead to the mixed equilibrium probabilities $(\gamma=0,(1-\gamma)=1)$ and $(\Delta=1 / 3,(1-\Delta)=2 / 3)$. If the profit obtained by the firm depends on the outcome from the project, these probabilities can be used to provide an approximation to the profit expected to be received by the firm. That is, given the identical set of pure Nash equilibria, the mixed strategy ones can be compared to determine which one leads to a higher expected profit for the firm. We will return to this topic at the end of this section.

Consider now the scenario presented in Table $\mathrm{V}$, which provides a numerical version of the strategic framework described in $\beta<\beta$ Table III.

Note that, in this case, the managers are those with an incentive to defect but not the employees. The payoff imbalances are not sufficiently large to satisfy the requirements of the managers, who shade by underperforming. The magnitude of these imbalances defines the intensity of shading by the managers, and, at the same time, this intensity determines the value of the defect payoff but does not modify the set of Nash equilibria of the game. Note that the pure Nash equilibria are also given by the (defect, cooperate) and (cooperate, defect) strategy pairs, as was the case in the previous framework. Moreover, a mixed strategy Nash equilibrium can also be calculated in the current setting based on the following equations:

$$
\begin{aligned}
& 4(1-\gamma)=3 \\
& 2(1-\Delta)=2
\end{aligned}
$$

These equations lead to the mixed equilibrium probabilities $(\gamma=1 / 4,(1-\gamma)=3 / 4)$ and $(\Delta=0,(1-\Delta)=1)$. Assume now that the profit of the firm depends on the outcome of the project. The mixed equilibrium probabilities of the strategic settings described in Tables II and III can be compared to determine which one leads to a higher expected profit for the firm. To do so, assume that firms use the highest potential defect probability obtained when at least one of the types of DMs follows their corresponding mixed strategy. The resulting comparison implies that the probability of coordinating on the (cooperate, cooperate) equilibrium equals $(2 / 3) \times(1 / 2)$ when the employees defect and $(3 / 4) \times(1 / 2)$ when the managers defect.

Table V.

Coordination-based payoffs within the $\beta<\underline{\beta}$ framework: manager defect incentives

\begin{tabular}{lclcc}
\hline & & & Managers \\
& & $\begin{array}{c}\Delta \\
(1-\Delta) \\
\text { Cooperate }\end{array}$ \\
\hline Employees & $\gamma$ & Defect & $0 ; 0$ & $2 ; 3$ \\
& $(1-\gamma)$ & Cooperate & $2 ; 4$ & $2 ; 3$ \\
\hline
\end{tabular}


More specifically, consider the probability assigned to the four potential scenarios that result in a (cooperate, cooperate) equilibrium within the strategic environment analyzed. Given the mixed equilibrium strategies of both types of DMs, the probability of both of them cooperating is given by a convex combination of the following four probability pairs:

(1) employees follow their mixed strategy and managers randomize: $(1-\gamma)(1 / 2)$;

(2) managers follow their mixed strategy and employees randomize: $(1-\Delta)(1 / 2)$;

(3) managers and employees follow their mixed strategies: $(1-\gamma)(1-\Delta)$; and

(4) managers and employees randomize: 1/2(1/2).

Note that because $(1-\Delta)=\alpha /\left(\alpha+\psi^{e}\right)$ is lower than $(1-\gamma)=\beta /\left(\beta+\psi^{M}\right)$ whenever $\psi^{e}=\psi^{M}$, it is easy to show that the subjective assignment of probability by the firm to any of these potential equilibrium scenarios will tend to lead defection by the managers to have a lower negative effect on its expected profit than defection by the employees. For illustrative purposes, assume that the firm assigns identical probabilities to each potential equilibrium scenario. Then, using the numerical payoffs provided in the examples, we have the following (cooperate, cooperate) probabilities within the four potential equilibrium scenarios considered:

(1) Only managers have an incentive to defect:

$$
\frac{1}{4}\left(\frac{\left(\frac{3}{4}\right)\left(\frac{1}{2}\right)}{(1-\gamma)\left(\frac{1}{2}\right)}+\frac{(1)\left(\frac{1}{2}\right)}{(1-\Delta)\left(\frac{1}{2}\right)}+\frac{\left(\frac{3}{4}\right)(1)}{(1-\gamma)(1-\Delta)}+\frac{\frac{1}{2}\left(\frac{1}{2}\right)}{\frac{1}{2}\left(\frac{1}{2}\right)}\right)
$$

(2) Only employees have an incentive to defect:

$$
\frac{1}{4}\left(\frac{(1)\left(\frac{1}{2}\right)}{(1-\gamma)\left(\frac{1}{2}\right)}+\frac{\left(\frac{2}{3}\right)\left(\frac{1}{2}\right)}{(1-\Delta)\left(\frac{1}{2}\right)}+\frac{\left(\frac{2}{3}\right)(1)}{(1-\gamma)(1-\Delta)}+\frac{\frac{1}{2}\left(\frac{1}{2}\right)}{\frac{1}{2}\left(\frac{1}{2}\right)}\right)
$$

(3) Both types of DMs have an incentive to defect:

$$
\frac{1}{4}\left(\frac{\left(\frac{3}{4}\right)\left(\frac{1}{2}\right)}{(1-\gamma)\left(\frac{1}{2}\right)}+\frac{\left(\frac{2}{3}\right)\left(\frac{1}{2}\right)}{(1-\Delta)\left(\frac{1}{2}\right)}+\frac{\left(\frac{3}{4}\right)\left(\frac{2}{3}\right)}{(1-\gamma)(1-\Delta)}+\frac{\frac{1}{2}\left(\frac{1}{2}\right)}{\frac{1}{2}\left(\frac{1}{2}\right)}\right)
$$

(4) None of them have an incentive to defect:

$$
\frac{1}{4}\left(\frac{(1)\left(\frac{1}{2}\right)}{(1-\gamma)\left(\frac{1}{2}\right)}+\frac{(1)\left(\frac{1}{2}\right)}{(1-\Delta)\left(\frac{1}{2}\right)}+\frac{(1)(1)}{(1-\gamma)(1-\Delta)}+\frac{\frac{1}{2}\left(\frac{1}{2}\right)}{\frac{1}{2}\left(\frac{1}{2}\right)}\right)
$$


The expected profit received by the firm is higher whenever both types of DMs have no incentive to defect. This is followed by the scenario where only the managers have an incentive to defect, then the employees and finally both types of DMs. This result has been obtained given the uniform distribution applied by the firm to the different equilibrium scenarios, which intends to reflect the maximum information entropy inherent to its decision process (Tavana et al., 2015). Different results would be obtained if the firm exhibits a specific bias toward a given scenario.

However, it is clear from the numerical example above that there is a larger set of probability assignments leading defection by the managers to have a lower negative effect on expected profits than defection by the employees. Thus, from a mixed Nash equilibrium perspective and given identical shading intensities by both groups of DMs, defections by the managers have a less negative effect on the expected profit of the firm when compared to those of the employees.

Intuitively, the equilibrium in mixed strategies leading to cooperation is determined by a variable $\theta$ that depends on the relative payoff from shading obtained by a given subset of DMs. This $\theta$ variable, whose value will differ between the $\beta>\bar{\alpha}$ and the $\beta<\underline{\beta}$ scenario based on the relative payoffs obtained by the different groups of DMs, is defined as follows:

$$
\theta=\frac{\text { payoff without shading }}{\text { payoff with shading }}
$$

This fraction is bounded within the interval $[0,1]$ because the denominator is always at least as large as the numerator. Cooperation will be fostered when both payoffs are similar but will be deterred when payoff differentials between both strategies (cooperating and defecting) differ substantially. Thus, if the managers can derive a substantial gain from shading, then the mixed equilibrium probability applied by the employees will bias toward defecting. A similar intuition follows when the employees derive a substantial gain from shading. In this case, the managers will defect with a higher probability. Thus, cooperation will be determined by the intensity of shading and the relative payoffs obtained by each group of DMs when they shade.

\section{Game theoretical structure: mixed equilibria and shading incentives}

This section defines formally the defect probabilities arising from the mixed strategy equilibria of the set games described in the previous sections. These probabilities are determined by the specific assumptions imposed when defining the shading parameters within the corresponding games, i.e. either $\psi^{M}(\alpha, \beta), \psi^{e}(\alpha, \beta)$ or both. In the current section, we will explicitly define both these parameters as variables determined endogenously by the payoff differentials between DMs and a subjective intensity variable with which employees and managers are, respectively, endowed.

Consider first the $\beta>\bar{\alpha}$ framework, corresponding to the games presented in Tables II and IV. Within this environment, the employees have an incentive to defect, leading managers to define the following mixed strategy equilibrium condition:

$$
\left(\alpha+(\beta-\bar{\alpha})^{\delta}\right)(1-\Delta)=\alpha
$$

which gives place to the defect probability implemented by the managers to contain the shading incentives of the employees: 


$$
1-(1-\Delta)=1-\left[\frac{\alpha}{\left(\alpha+(\beta-\bar{\alpha})^{\delta}\right)}\right]
$$

Managing team

coordination incentives

We have defined the shading incentives of employees within this equation as $\psi^{e}$ $(\alpha, \beta)=(\beta-\bar{\alpha})^{\delta}$. As stated above, the intensity of shading is determined by the distance between the payoff received by the managers, $\beta$, and the shading limit defined by the employees, $\bar{\alpha}$. At the same time, we have introduced an intensity parameter, $\delta \geq 1$, whose value determines the subjective payoff derived by employees from shading.

Similarly, we can analyze the $\beta<\beta$ framework corresponding to the games presented in Tables III and V. In this case, the mixed strategy equilibrium condition is defined by the employees, who try to contain the shading incentives of the managers:

$$
\left(\beta+(\underline{\beta}-\beta)^{\eta}\right)(1-\gamma)=\beta
$$

giving place to the following defect probability:

$$
1-(1-\gamma)=1-\left[\frac{\beta}{\left(\beta+(\underline{\beta}-\beta)^{\eta}\right)}\right]
$$

As done with the employees, the shading variable of the managers has been defined as $\psi^{M}(\alpha, \beta)=(\beta-\beta)^{\eta}$. In this case, the intensity of shading is determined by the relative distance between the minimum payoff required by the managers, $\beta$, and the one received, $\beta$. We have also assumed that a subjective intensity parameter, $\eta \geq 1$, determines the payoff from shading after accounting for the compensation differentials required by the managers.

We can now compare the defect probabilities defined by managers and employees because their subjective intensity parameters, $\eta$ and $\delta$, and shading limits, $\beta$ and $\bar{\alpha}$, are modified. This has been done in Figure 7, where the default probabilities of managers and employees are represented within the $\alpha=10$ and $\beta \in\left[\begin{array}{ll}10 & 20\end{array}\right]$ environment. Moreover, the shading areas of the blue and green functions are delimited by $\bar{\alpha}=$ $\underline{\beta}=15$, whereas the purple one is based on $\bar{\alpha}=\underline{\beta}=12$.

Note that the default probabilities of the employees, $1-\left[\alpha /\left(\alpha+(\beta-\bar{\alpha})^{\delta}\right)\right]$, are represented on the left hand side of the corresponding $\bar{\alpha}=\beta$ shading limit because they have to compensate for the incentives of the managers to defect. Similarly, the default probabilities of the managers, $1-\left[\beta /\left(\beta+(\underline{\beta}-\beta)^{\eta}\right)\right]$, are represented on the right hand side of the shading limit, compensating for the incentives of the employees to shade within the corresponding game. In this regard, the blue and purple functions are based on the $\eta=\delta=2$ intensity parameters, whereas the green function describes the $(\eta=$ $2, \delta=3$ ) case.

Clearly, we have an increment in the defect probability in all the scenarios as the distance between the shading limit and the corresponding $\beta$ value increases. Note, in particular, the symmetry is observed in the case with $\bar{\alpha}=\underline{\beta}=15$ and $\eta=\delta=2$, whereas different cumulative patterns arise when $\bar{\alpha}=\underline{\beta}=12$ and $\delta=3$ :

- In the former case, due to the decrease in the value of $\beta$, employees require a smaller defect probability to compensate for the shading incentives of managers. On the other hand, the wider $\beta>\bar{\alpha}$ interval leads managers to define an increasingly higher defect probability to prevent employees from shading. 


\section{JCC \\ 9,1}

\section{6}

Figure 7.

Defect probability of the managers and the employees with different intensities and shading limits

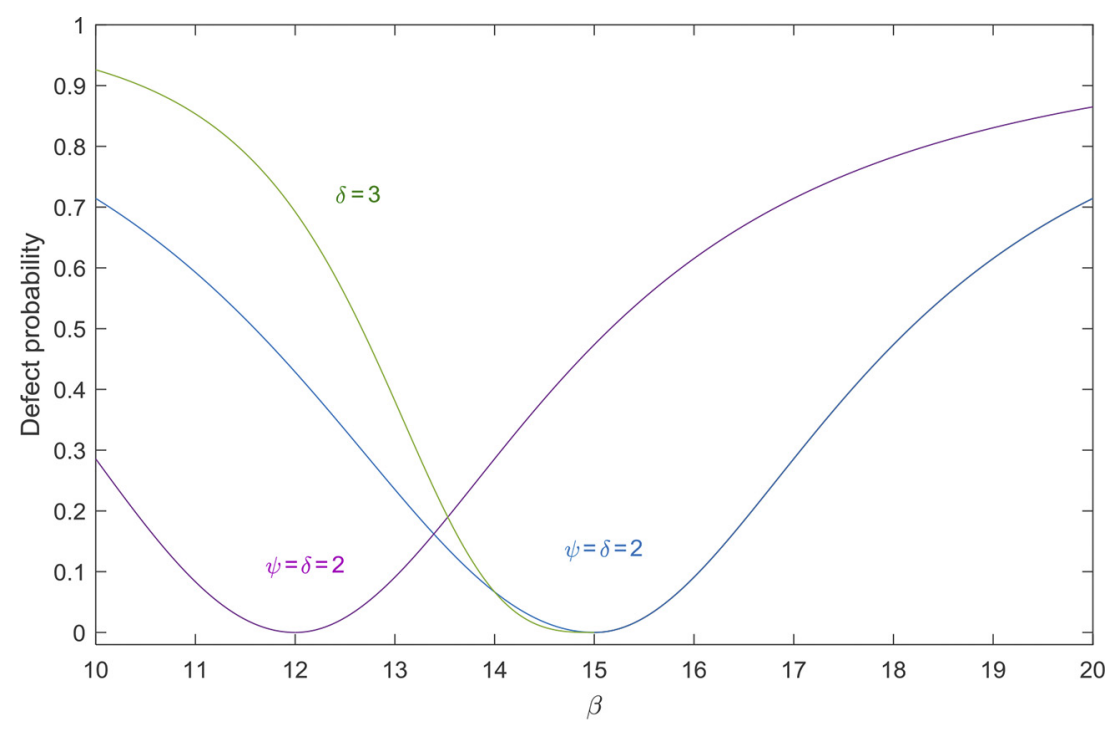

Note: Separated shading areas

- In the latter case, we observe how the defect probability computed by the employees increases in the value of the intensity parameter - and the relative distance of the payment received by the managers below $\underline{\beta}$.

To provide additional intuition, we have represented in Figure 8 the overlapping shading setting described in Figure 5. That is, Figure 8 illustrates the defect probability of the managers and the employees within the $\alpha=10$ and $\beta \in$ $\left[\begin{array}{ll}10 & 20\end{array}\right]$ scenario when the shading areas are delimited by $\bar{\alpha}=12$ and $\underline{\beta}=17$. At the same time, the intensity parameters of the blue functions are given by $\eta=\delta=2$, whereas those of the green functions correspond to the $\eta=\delta=3$ case. Clearly, the behavioral patterns of managers and employees described in Figure 7 can also be observed in this figure, together with the joint defection incentives of both types of DMs within the [12 17 $]$ interval. In this case, both types of DMs have an incentive to shade, leading the other to increase their defect probabilities to prevent the occurrence of a shading equilibrium.

Finally, it should be emphasized that the strategic environment described through the paper has taken the subjective intensity parameters of DMs as given, though they could be determined by several factors, ranging from the degree of inequality aversion to the existence of envy in the preferences of the DM.

Thus, we conclude this section by illustrating in Figure 9 the relationship between the shading intensity of employees and the resulting defect probability of managers within the $\alpha=10$ and $\delta \in\left[\begin{array}{ll}1 & 5\end{array}\right]$ scenario, i.e. when allowing for different values of the intensity parameter of employees. This figure illustrates the cumulative property of the defect probability of managers determined by the width of the interval defined through different shading limits, $\bar{\alpha}=10, \bar{\alpha}=15$ and $\bar{\alpha}=$ 18. The intuition justifying the inclusion of this latter figure relates to the possibility 


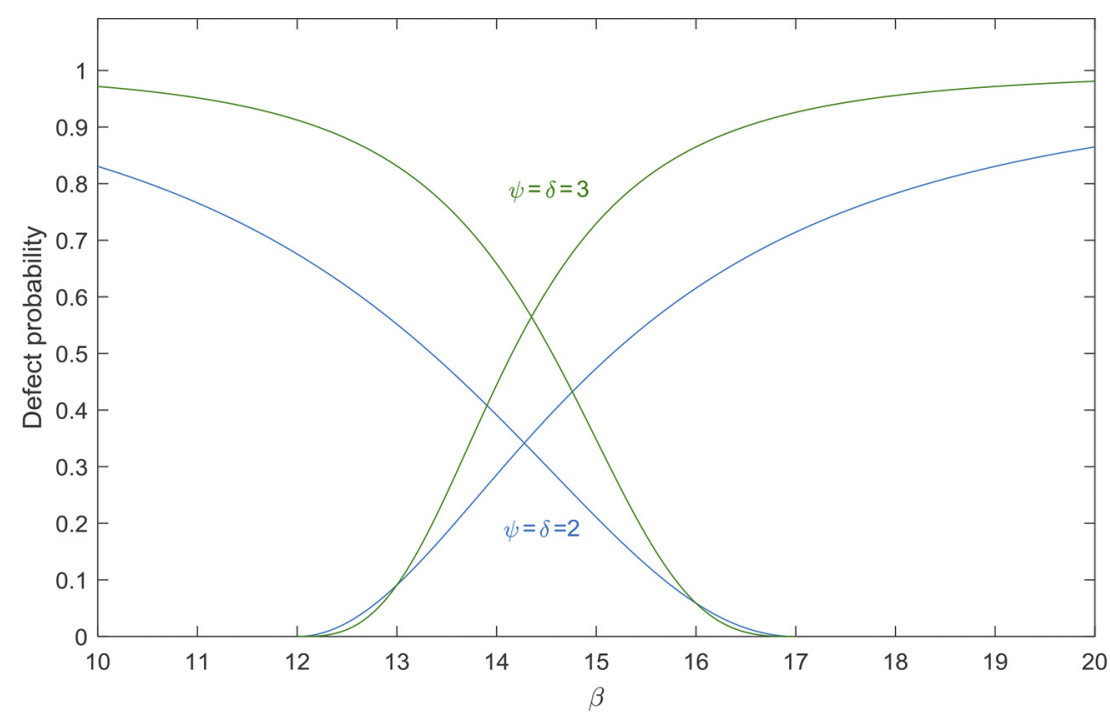

Note: Overlapping shading areas

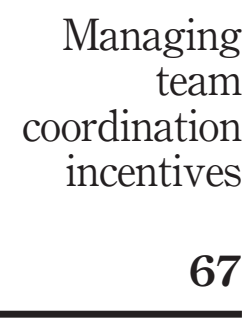

Figure 8.

Defect probability of the managers and the employees with different intensities and shading limits

of defining a Bayesian signaling game whose equilibria are determined by the potential subjective values of the intensity parameters and the shading limits defined by both types of DMs.

\section{Conclusion}

The current paper has introduced a formal model illustrating how payoff imbalances among the members of a team of DMs who must develop a coordinated project condition the final outcome obtained by the firm. We have shown how a team-based performance reward structure may achieve a coordinated equilibrium even when team managers and employees receive different payoffs and exhibit shading incentives based on the payoff differentials between them. The resulting strategic defect mechanism determined by differences in shading intensity between both types of DMs has been analyzed. We have also illustrated how, given identical shading intensities by both groups of DMs, shading by the managers imposes a lower cost on the expected profit obtained by the firm from the outcome of the project.

The dependence of the shading intensity applied by the DMs on the relative payoff imbalances observed constitutes the main contribution of the strategic environment introduced in the current paper. This property of the shading intensities allows the resulting model to account for a variety of scenarios where payoff differentials among DMs determine the equilibrium of the coordination game and the resulting outcome of the project being developed.

One of the main limitations arising from the type of strategic environments defined within this branch of the literature is the constraint imposed on the number of different types of DMs composing a team. In other words, only two types of DMs have been considered, though a more heterogeneous environment consisting of several additional 


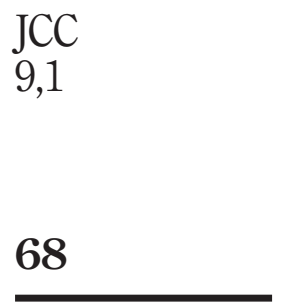

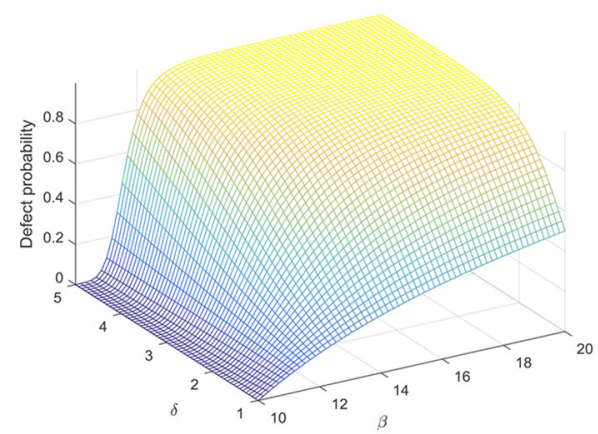

(a) $\bar{\alpha}=10$ and $\beta \in[1020]$

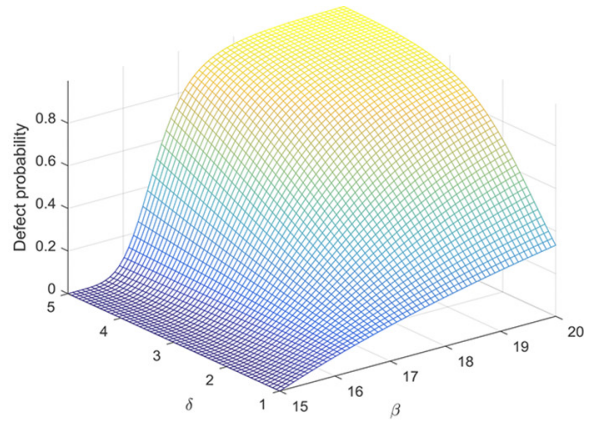

(b) $\bar{\alpha}=15$ and $\beta \in[1520]$

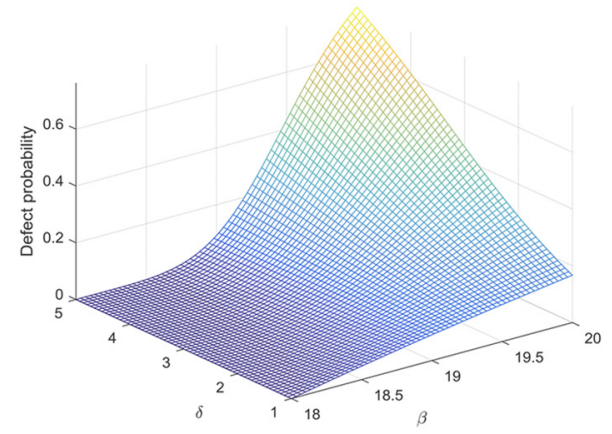

(b) $\bar{\alpha}=18$ and $\beta \in\left[\begin{array}{ll}18 & 20\end{array}\right]$

Figure 9.

Defect probability of the managers
Notes: $1-(1-\Delta)=1-\left[\frac{\alpha}{\left(\alpha+(\beta-\bar{\alpha})^{\delta}\right)}\right]$ with $\alpha=10$ and $\delta \in\left[\begin{array}{ll}1 & 5\end{array}\right]$

types of DMs would provide a better fit to real life situations. Clearly, the subsequent framework should focus on the critical mass of DMs required for a project to fail, with different degrees of defection - determined by the number and type of groups shading resulting in different project efficiency levels.

An immediate extension of the current model could consider a stochastic environment, where the payoffs received by the DMs are unknown, turning the resulting shading variables into either random or fuzzy variables. As suggested in the previous section, this type of framework would require defining a Bayesian signaling game whose equilibria would be determined by the potential values of the intensity parameters and the shading limits defined by both types of DMs. Moreover, this extension would also allow us to consider additional stochastic scenarios not only within the current project cooperation environment but also when selecting different technological information transmission structures within a strategic management setting (Nickerson and Zenger, 2008; Argyres et al., 2015). That is, different technological structures would become optimal given the expected differences in the project payoffs obtained by the members of each group of DMs. 


\section{References}

Adams, J.S. (1963), “Toward an understanding of inequity”, Journal of Abnormal and Social Psychology, Vol. 67 No. 5, pp. 422-436.

Afcha Chavez, S.M. (2014), "An exploration of the relationship between high performance work systems and job satisfaction”, Journal of CENTRUM Cathedra: The Business and Economics Research Journal, Vol. 7 No. 2, pp. 147-166.

Alchian, A.A. and Demsetz, H. (1972), "Production, information costs, and economic organization”, American Economic Review, Vol. 62 No. 5, pp. 777-795.

Argyres, N., Bigelow, L. and Nickerson, J.A. (2015), "Dominant designs, innovation shocks, and the follower's dilemma”, Strategic Management Journal, Vol. 36 No. 2, pp. 216-234.

Bamberg, G., Spremann, K. (1987), Agency Theory, Information, and Incentives, Springer-Verlag, Berlin.

Bartling, B. and Von Siemens, F.A. (2010), "The intensity of incentives in firms and markets: moral hazard with envious agents", Labour Economics, Vol. 17 No. 3, pp. 598-607.

Blinder, A.S. and Choi, D.H. (1990), “A shred of evidence on theories of wage stickiness”, Quarterly Journal of Economics, Vol. 105 No. 4, pp. 1003-1015.

Chion, S.J. and Charles, V. (2016), "Impact of incentive schemes and personality-tradeoffs on two-agent competition: a theoretical examination", CENTRUM Working Paper 2016-06-0027.

Cohn, A., Fehr, E., Herrmann, B. and Schneider, F. (2012), "Social comparison and effort provision: evidence from a field experiment”, IZA Discussion Paper No. 5550, Institute for the Study of Labor, Bonn.

Faulkender, M.W. and Yang, J. (2010), "Inside the black box: the role and composition of payoff peer groups”, Journal of Financial Economics, Vol. 96 No. 2, pp. 257-270.

Festinger, L. (1954), “A theory of social comparison processes”, Human Relations, Vol. 7 No. 2 , pp. 117-140.

Foss, N.J. and Nielsen, B.B. (2012), "Researching multilevel phenomena: the case of collaborative advantage in strategic management", Journal of CENTRUM Cathedra: The Business and Economics Research Journal, Vol. 5 No. 1, pp. 11-23.

Foss, N.J. and Weber, L. (2016), "Moving opportunism to the back seat: bounded rationality, costly conflict, and hierarchical forms", Academy of Management Review, Vol. 41 No. 1, pp. 61-79.

Garcia, S.M., Tor, A. and Schiff, T.M. (2013), “The psychology of competition: a social comparison perspective", Perspectives on Psychological Science, Vol. 8 No. 6, pp. 634-650.

Gibbons, R. and Roberts, J. (Eds) ( 2013), "Economic theories of incentives in organizations", The Handbook of Organizational Economics, Princeton University Press, NJ.

Gino, F. and Pierce, L. (2010), "Robin Hood under the hood: wealth-based discrimination in illicit customer help”, Organization Science, Vol. 21 No. 6, pp. 1176-1194.

Hart, O. and Holmstrom, B. (2010), "A theory of firm scope”, Quarterly Journal of Economics, Vol. 125 No. 2, pp. 483-513.

Hart, O. and Moore, J. (2008), "Contracts as reference points", Quarterly Journal of Economics, Vol. 123 No. 1, pp. 1-48.

Holmstrom, B. (1979), "Moral hazard and observability", Bell Journal of Economics, Vol. 10 No. 1, pp. 74-91.

Homans, G.C. (1961), Social Behavior: Its Elementary Forms, Harcourt, Brace \& World, New York, NY. 
JCC

9,1

Jensen, M.C. and Meckling, W. (1976), "Theory of the firm: managerial behavior, agency costs, and ownership structure", Journal of Financial Economics, Vol. 3 No. 4, pp. 305-360.

Kostova, T., Nell, P.C. and Hoenen, A.K. (2016). "Understanding agency problems in headquarters-subsidiary relationships in multinational corporations: a contextualized model", Journal of Management, doi: 10.1177/0149206316648383.

Laffont, J.J. and Martimort, D. (2001), The Theory of Incentives: The Principal-Agent Model, Princeton University Press, NJ.

Larkin, I., Pierce, L. and Gino, F. (2012), "The psychological costs of pay-for-performance: implications for the strategic payoff of employees", Strategic Management Journal, Vol. 33 No. 10, pp. 1194-1214.

Meyer, H.H. (1975), “The pay-for-performance dilemma”, Organizational Dynamics, Vol. 3 No. 3, pp. 39-49.

Nickerson, J.A. and Zenger, T.R. (2008), "Envy, comparison costs, and the economic theory of the firm”, Strategic Management Journal, Vol. 29 No. 13, pp. 1429-1449.

Pepper, A., Gosling, T. and Gore, J. (2015), "Fairness, envy, guilt and greed: building equity considerations into agency theory", Human Relations, Vol. 68 No. 8, pp. 1291-1314.

Pérez-Arechaederra, D., García Ortiz, L. and Mora Simón, S. (2014), "Perceived procedural organizational justice matters for the success of quality policies", Journal of CENTRUM Cathedra: The Business and Economics Research Journal, Vol. 7 No. 2, pp. 179-188.

Suls, J. and Wheeler, L. (Eds) ( 2000), "Handbook of social comparison", Theory and Research, Springer, New York, NY.

Tavana, M., Di Caprio, D., Santos-Arteaga, F.J. and O'Connor, A. (2015), “A novel entropy-based decision support framework for uncertainty resolution in the initial subjective evaluations of experts: the NATO enlargement problem", Decision Support Systems, Vol. 74, pp. 135-149.

Zenger, T.R. (1994), "Explaining organizational diseconomies of scale in R\&D: agency problems and the allocation of engineering talent, ideas, and effort by firm size”, Management Science, Vol. 40 No. 6, pp. 708-729.

\section{Corresponding author}

Madjid Tavana can be contacted at: tavana@lasalle.edu

For instructions on how to order reprints of this article, please visit our website:

www.emeraldgrouppublishing.com/licensing/reprints.htm

Or contact us for further details: permissions@emeraldinsight.com 